\title{
GAMBARAN KONDISI PERUMAHAN DI DESA SUKOSARI KECAMATAN BARADATU KABUPATEN WAY KANAN
}

\author{
Rina Diana Sari ${ }^{1)}$
}

\begin{abstract}
Abstrak
Rumah merupakan salah satu kebutuhan pokok manusia. Konstruksi rumah dan lingkungan yang tidak memenuhi syarat kesehatan merupakan faktor risiko terhadap berbagai jenis penyakit. Penelitian bertujuan mendapatkan gambaran kondisi kesehatan perumahan di Desa Sukosari Kecamatan Baradatu Kabupaten Way Kanan. Variabel yang diteliti adalah langit-langit, dinding lantai, jendela kamar tidur, jendela ruang keluarga, ventilasi, sarana pembuangan asap dapur, dan pencahayaan.

Jenis penelitian adalah deskriptif, untuk mendapatkan gambaran kondisi kesehatan perumahan. Populasi penelitian adalah seluruh rumah yang berjumlah 297 rumah. Sampel sebanyak 75 rumah, dipilih secara acak dengan teknik systematic random sampling. Keseluruhan data dibandingkan dengan Keputusan Menteri Kesehatan RI Nomor 829/Menkes/SK/VII/1999, tentang persyaratan kesehatan perumahan.

Hasil penelitian mendapatkan bahwa secara umum kondisi kesehatan perumahan masih kurang baik. Sebanyak $80 \%$ rumah tinggal belum dilengkapi langit-langit, dinding rumah masih semi permanen $(17,3 \%)$, dan lantai tanah $(14,7 \%)$. Mayoritas rumah tinggal telah memiliki jendela kamar tidur $(85,3 \%)$ dan jendela pada ruang keluarga $(88,0 \%)$. Sehingga penerangan pada $72,0 \%$ rumah telah memenuhi syarat kesehatan (50-100 lux). Namun hanya 29,3\% rumah yang memiliki ventilasi memenuhi syarat kesehatan, dan sebagian besar $(72,0 \%)$ tidak memiliki lubang asap dapur.

Perlu peningkatan pengetahuan masyarakat tentang rumah sehat serta kaitannya dengan penyakit. Metode penyuluhan secara langsung dan penggunaan media menjadi pilihan dalam proses perubahan perilaku masyarakat. Dibutuhkan keterlibatan semua pihak dalam upaya meningkatkan cakupan rumah sehat, dan penurunan angka penyakit.
\end{abstract}

Kata Kunci : Rumah Sehat, Komponen Rumah

${ }^{1)}$ Alumni Jurusan Kesehatan Lingkungan Poltekkes Kemenkes Tanjungkarang

\section{PENDAHULUAN}

Di berbagai negara berkembang termasuk Indonesia, upaya kesehatan lingkungan merupakan salah satu upaya dalam program kesehatan. Kesehatan adalah keadaan sejahtera dari badan, jiwa, dan sosial yang memungkinkan hidup produktif secara sosial dan ekonomi (Adnani, 2011).

Kesehatan lingkungan merupakan suatu kondisi atau keadaan lingkungan yang optimum sehingga berpengaruh positif terhadap terwujudnya status kesehatan masyarakat yang optimal. Menurut WHO, kesehatan lingkungan adalah ilmu yang memusatkan perhatiannya pada usaha pengendalian semua faktor yang ada pada lingkungan fisik manusia yang diperkirakan menimbulkan atau akan menimbulkan hal-hal yang merugikan perkembangan fisiknya, kesehatannya maupun kelangsungan hidupnya (Adnani, 2011).
Rumah adalah sebagai tempat untuk melepas lelah, beristirahat setelah penat, melaksanakan kewajiban sehari-hari, tempat untuk bergaul dengan keluarga dan membina rasa kekeluargaan bagi segenap anggota keluarga yang ada, tempat untuk meletakkan atau menyimpan barang-barang berharga yang dimiliki, yang terutama masih ditemui pada masyarakat pedesaan, lambang status sosial yang dimiliki, yang masih dirasakan hingga saat ini (Riviwanto, dkk, 2011). Rumah sehat sebagai tempat tinggal yang memenuhi ketetapan atau ketentuan teknis kesehatan yang wajib dipenuhi dalam rangka melindungi penghuni rumah dari bahaya atau gangguan kesehatan sehingga memungkinkan penghuni memperoleh derajat kesehatan yang optimal (Adnani, 2011).

Konstruksi rumah dan lingkungan yang tidak memenuhi syarat kesehatan merupakan 
faktor risiko penularan berbagai jenis penyakit. Kondisi sanitasi perumahan yang tidak memenuhi syarat dapat menjadi penyebab penyakit, seperti infeksi saluran pernafasan akut dan TB Paru (Entjang, 2000). Unsur-unsur rumah yang perlu diperhatikan untuk memenuhi rumah sehat antara lain bahan bangunan, ventilasi, pencahayaan, luas bangunan rumah, penyediaan air bersih, pembuangan tinja, pembuangan air limbah, pembuangan sampah, dan fasilitas dapur (Adnani, 2011).

Kabupaten Way Kanan memiliki luas $392.163 \mathrm{Ha}$, dengan jumlah penduduk sekitar 423.195 jiwa. Salah satu wilayah dengan kepadatan tertinggi adalah Kecamatan Baradatu. Luas wilayah kerja Puskesmas Baradatu sekitar 17.255 Ha, dengan jumlah penduduk 39.007 jiwa yang terdistribusi dalam 22 desa (Profil Badan Pusat Statistik Kabupaten Way Kanan tahun 2014).

Berdasarkan data Puskesmas Baradatu tahun 2014, Desa Sukosari merupakan desa dengan cakupan rumah sehat yang terendah. Dari total 297 rumah, hanya 30,30\% yang memenuhi syarat rumah sehat. Penelitian bertujuan mengetahui gambaran kondisi kesehatan perumahan, melalui penilaian komponen rumah sehat, meliputi langit-langit, dinding, lantai, jendela kamar tidur, jendela ruang keluarga, ventilasi, lubang asap dapur, dan pencahayaan.

\section{METODE}

Penelitian ini bersifat deskriptif untuk mengambarkan tentang kondisi perumahan di Desa Sukosari Kecamatan Baradatu Kabupaten Way Kanan. Populasi penelitian adalah seluruh rumah, sebanyak 297 rumah. Jumlah sampel pada penelitian ini sebanyak 75 rumah, dipilih dengan teknik systematic random sampling.

Penelitian dilaksanakan pada bulan Juni 2015. Variabel yang diteliti adalah komponen rumah sehat, meliputi langit-langit, dinding, lantai, jendela kamar tidur, jendela ruang keluarga, ventilasi, lubang asap dapur, dan pencahayaan.

Data dikumpulkan dengan observasi dan wawancara menggunakan kuesioner dan checklist. Pengukuran juga dilakukan untuk mendapatkan penilaian yang tepat pada variabel luas jendela, luas lubang asp dapur dan pencahayaan dalam rumah. Data yang dikumpulkan selanjutnya dibandingkan dengan Keputusan Menteri Kesehatan RI Nomor
829/Menkes/SK/VII/1999, tentang persyaratan kesehatan perumahan.

\section{HASIL}

Hasil penelitian mendapatkan (Tabel 1) bahwa dari 75 rumah yang dinilai, sebanyak 60 rumah $(80,0 \%)$ tidak memiliki langit-langit, 10 rumah $(13,3 \%)$ memiliki langit-langit yang kotor, sulit dibersihkan dan rawan kecelakaan, dan 5 rumah $(6,7 \%)$ memiliki langit-langi yang bersih, mudah dibersihkan, dan tidak rawan kecelakaan.

Berdasarkan dinding rumah, tidak ditemukan rumah yang menggunakan dinding non permanen. Sebanyak 13 rumah $(17,3 \%)$ memiliki dinding semi permanen, dan 62 rumah $(82,7 \%)$ dinding permanen, terbuat dari pasangan bata diplester dan kedap air.

Rumah yang lantainya dari tanah sebanyak 11 rumah $(14,7 \%)$, lantai tidak kedap air dan tidak mudah dibersihkan sebanyak 13 rumah $(17,3 \%)$, dan rumah dengan lantai kedap air dan mudah dibersihkan sebanyak 51 rumah $(68,0 \%)$.

Hasil penelitian juga mendapatkan bahwa sebanyak 64 rumah $(85,3 \%)$ telah memilki jendela pada kamar tidur, namun terdapat 11 rumah $(14,7 \%)$ yang memilki. Pada komponen penilaian jendela ruang keluarga, sebanyak 66 rumah $(88,0 \%)$ telah memilki jendela ruang keluarga, namun masih terdapat 9 rumah $(12,00 \%)$ yang tidak memiliki jendela ruang keluarga.

Berdasarkan penilaian komponen ventilasi, penelitian mendapatkan sebanyak 12 rumah $(16,0 \%)$ tidak ada ventilasi, 41 rumah $(54,7 \%)$ telah memiliki ventilasi namun luasnya $<10 \%$ dari luas lantai). Hanya sebanyak 22 rumah $(29,3 \%)$ yang memiliki ventilasi memenuhi syarat kesehatan (minimal $10 \%$ luas lantai).

Pada Tabel 1 juga terlihat bahwa jumlah rumah yang tidak ada lubang asap dapur sebanyak 54 rumah (72,0\%). Rumah yang memiliki lubang asap dapur tetapi luasnya kurang dari $10 \%$ dari luas dapur sebanyak 19 rumah $(25,3 \%)$, dan rumah yang memiliki lubang asap dapur dengan luas lebih dari $10 \%$ luas dapur sebanyak 2 (dua) rumah $(2,67 \%)$.

Hasil pengukuran pencahayaan dalam rumah mendapatkan bahwa sebanyak 21 rumah $(28,0 \%)$ masuk dalam kategori gelap (<50 lux), dan 37 rumah $(72,0 \%)$ masuk dalam kategori terang (50-100 lux). 
Tabel 1. Hasil Survei Rumah

\begin{tabular}{|c|c|c|c|}
\hline No & Komponen Penilaian & Jumlah & $\begin{array}{c}\text { Persentas } \\
\text { e }(\%)\end{array}$ \\
\hline \multirow[t]{4}{*}{1} & Langit-langit & & \\
\hline & Tidak ada & 60 & 80,0 \\
\hline & Ada, kotor, sulit dibersihkan, dan rawan kecelakaan & 10 & 13,3 \\
\hline & Ada, bersih, mudah dibersihkan, dan tidak rawan kecelakaan & 5 & 6,7 \\
\hline \multirow[t]{4}{*}{2} & Dinding & & \\
\hline & Non permanen & 0 & 0,0 \\
\hline & Semi Permanen & 13 & 17,3 \\
\hline & Permanen & 62 & 82,7 \\
\hline \multirow[t]{4}{*}{3} & Lantai & & \\
\hline & Tanah & 11 & 14,7 \\
\hline & Tidak kedap air dan tidak mudah dibersihkan & 13 & 17,3 \\
\hline & Kedap air dan mudah dibersihkan & 51 & 68,0 \\
\hline \multirow[t]{3}{*}{4} & Jendela kamar tidur & & \\
\hline & Ada & 64 & 85,3 \\
\hline & Tidak ada & 11 & 14,7 \\
\hline \multirow[t]{3}{*}{5} & Jendela ruang keluarga & & \\
\hline & Ada & 66 & 88,0 \\
\hline & Tidak ada & 9 & 12,0 \\
\hline \multirow[t]{4}{*}{6} & Ventilasi & & \\
\hline & Tidak ada & 12 & 16,0 \\
\hline & Ada, luas ventilasi permanen $<10 \%$ dari luas lantai & 41 & 54,7 \\
\hline & Ada, luas ventilasi permanen $>10 \%$ dari luas lantai & 22 & 29,3 \\
\hline \multirow[t]{4}{*}{7} & Lubang asap dapur & & \\
\hline & Tidak ada & 54 & 72,0 \\
\hline & Ada, lubang ventilasi dapur $<10 \%$ dari luas lantai dapur & 19 & 25,3 \\
\hline & Ada, lubang ventilasi dapur $>10 \%$ dari luas lantai dapur & 2 & 2,7 \\
\hline \multirow[t]{3}{*}{8} & Pencahayaan & & \\
\hline & Tidak terang, silau, dan pencahayaan alami $<50-100$ lux & 21 & 28,0 \\
\hline & Terang, tidak silau, dan pencahayaan alami 50-100 lux & 54 & 72,0 \\
\hline
\end{tabular}

\section{PEMBAHASAN}

\section{Langit-langit}

Berdasarkan survey yang telah dilaksanakan di Desa Sukosari Kecamatan Baradatu Kabupaten Way Kanan, diketahui sebanyak 60 rumah $(80,0 \%)$ tidak memiliki langit-langit, 10 rumah $(13,3 \%)$ memiliki langit-langit yang kotor, sulit dibersihkan dan rawan kecelakaan. Hanya 5 rumah $(6,7 \%)$ yang memiliki langitlangi bersih, mudah dibersihkan, dan tidak rawan kecelakaan.

Langit-langit berfungsi untuk menahan dan menyerap panas terik matahari. Selain berfungsi sebagai penutup bagian dalam konstruksi atap, langit-langit juga berfungsi sebagai penahan debu dan kotoran agar tidak masuk ke dalam rumah. Persyaratan langit-langit yang baik adalah dapat menahan debu dan kotoran lain yang jatuh dari atap, harus menutup rata kerangka atap, mudah dibersihkan, tidak rawan kecelakaan, berwarna terang, dan batas tinggi langit-langit dari lantai 2,75 m (Adnani, 2011).
Rumah yang tidak memiliki langit-langit dapat mengakibatkan masuknya debu atau kotoran ke dalam ruangan, sehingga kandungan partikel di udara dalam ruangan menjadi tinggi (Entjang, 2000). Apabila terhirup oleh penghuni rumah dapat berakibat pada infeksi saluran pernafasan.

Langit-langit juga berfungsi untuk menjaga suhu dan kelembaban dalam rumah (Keman, 2005). Energi panas matahari yang diserap oleh atap akan ditahan oleh langit-langit. Sehingga, pada siang hari suhu udara dalam rumah tidak terasa panas. Pada malam hari, panas yang tertahan akan meningkatkan suhu udara dalam rumah, sehingga tidak terasa dingin. Sebaiknya rumah yang belum memiliki langit-langit agar dapat memasang langit-langit agar kualitas udara dalam rumah menjadi baik.

\section{Dinding}

Hasil penelitian mendapatkan bahwa mayoritas $(82,7 \%)$ dinding rumah telah memenuhi persyaratan kesehatan, terbuat dari 
pasangan bata diplester dan kedap air. Namun masih terdapat $17,3 \%$ yang belum memenuhi syarat kesehatan.

Dinding rumah kedap air yang berfungsi untuk mendukung atau menyangga atap, menahan angin dan air hujan, melindungi dari panas dan debu dari luar serta menjaga kerahasiaan (privacy) penghuninya. Dinding yang baik terbuat dari yang tahan api, seperti dinding dari batu atau bata (Riviwanto, dkk, 2011).

Jenis dinding rumah yang tidak permanen dapat meningkatkan kelembaban udara dalam rumah (Keman, 2005). Tingginya kelembaban dalam rumah dapat meningkatkan pertumbuhan mikroorganisme, sehingga berisiko terhadap penyakit-penyakit infeksi saluran pernafasan. Kelembaban dalam rumah yang tinggi juga merupakan lingkungan yang disukai vektor sebagai tempat bersarang dan berbiak.

Sebaiknya lubang-lubang yang terdapat pada dinding rumah yang terbuat dari anyaman bambu dan papan dapat ditutup dengan kertas, terpal atau plastik untuk mengurangi masuknya debu dari luar rumah.

\section{Lantai}

Berdasarkan hasil survey yang telah dilaksanakan, ditemukan sebanyak 14,7\% rumah yang lantainya dari tanah, rumah dengan lantai tidak kedap air dan tidak mudah dibersihkan (17,3\%), dan rumah dengan lantai kedap air dan mudah dibersihkan $(68,0 \%)$.

Lantai yang memenuhi persyaratan kesehatan akan mengurangi gangguan penyakit terhadap penghuninya. Lantai perlu dilapisi dengan bahan yang kedap air (seperti disemen, dipasang tegel, terraso dan lain-lain) untuk menghindari terjadinya kecelakaan (Riviwanto, dkk, 2011).

Lantai dari tanah menyebabkan kelembaban dalam rumah menjadi tinggi akibat penguapan dari dalam tanah. Kelembaban ruangan yang tinggi akan berpengaruh terhadap peningkatan jumlah mikroba dalam rumah, sehingga meningkatkan risiko penyakit. Lantai tanah juga akan meningkatkan partikel di udara dalam rumah, sehingga meningkatkan risiko penyakit.

Untuk meningkatkan status kesehatan masyarakat, sebaiknya dilakukan perbaikan lantai rumah melalui program lantainisasi. Diperlukan keterlibatan Pemerintah Daerah dan semua pihak dalam upaya perbaikan.

\section{Jendela kamar tidur dan ruang keluarga.}

Hasil penelitian juga mendapatkan bahwa sebanyak 64 rumah $(85,3 \%)$ telah memilki jendela pada kamar tidur, namun terdapat 11 rumah $(14,7 \%)$ yang memilki. Pada komponen penilaian jendela ruang keluarga, sebanyak 66 rumah $(88,0 \%)$ telah memilki jendela ruang keluarga, namun masih terdapat 9 rumah $(12,00 \%)$ yang tidak memiliki jendela ruang keluarga.

Jendela berperan sebagai tempat masuknya sinar matahari ke dalam rumah, sekaligus sebagai lubang pertukaran udara (lubang ventilasi yang tidak tetap). Dengan adanya jendela sebagai lubang ventilasi dan lubang masuknya sinar matahari ini maka di dalam ruangan tidak akan terasa pengap, lembap dan gelap asalkan jendela selalu terbuka (Sukini dkk, 1989).

Rumah yang tidak masuk sinar matahari akan berdampak pada timbulnya ketidaknyamanan dan dapat berkaitan dengan infeksi penyaki, seperti saluran pernafasan. Tidak masuknya sinar matahari ke dalam rumah menyebabkan suhu ruangan menjadi rendah dan kelembaban menjadi tinggi. Kondisi ini akan meningkatkan pertumbuhan mikroorganisme, serta lingkungan yang sesuai untuk perkembangbiakan vektor.

Sebaiknya dilakukan perbaikan pada rumah yang belum memiliki jendela dengan pemasangan atau pembuatan jendel. Peningkatan pengetahuan masyarakat melalui penyuluhan harus dilakukan agar memahami pentingnya rumah sehat.

\section{Ventilasi}

Berdasarkan penilaian komponen ventilasi, penelitian mendapatkan sebanyak 12 rumah $(16,0 \%)$ tidak ada ventilasi, 41 rumah $(54,7 \%)$ telah memiliki ventilasi namun luasnya $<10 \%$ dari luas lantai). Hanya sebanyak 22 rumah $(29,3 \%)$ yang memiliki ventilasi memenuhi syarat kesehatan (minimal $10 \%$ luas lantai).

Ventilasi berfungsi sebagai tempat sirkulasi udara dari dan ke dalam rumah. Selain itu, ventilasi juga berfungsi untuk membebaskan udara ruangan dari bakteri-bakteri, karena selalu terjadi aliran udara yang terus-menerus. Fungsi lainnya adalah untuk menjaga agar ruangan rumah selalu tetap dalam kelembaban (humudity) yang optimum. (Notoatmodjo, 2007).

Luas ventilasi yang memenuhi syarat dapat membuat pergantian udara di dalam ruangan 
menjadi lancar, sehingga udara ruangan tetap segar. Udara segar diperlukan untuk menjaga temperatur dan kelembaban udara dalam ruangan. Kondisi ruangan yang lembap, sangat baik bagi pertumbuhan mikroorganisme (Keman, 2005). Ventilasi berkaitan dengan penularan penyakit, pertukaran udara dapat memecah konsentrasi kuman di udara. Ventilasi dinyatakan memenuhi syarat kesehatan jika luasnya minimal 10\% dari luas lantai" (Sukini, 1989).

Setiap rumah mutlak harus memiliki ventilasi pada setiap ruangan, agar udara di dalam rumah tidak pengap. Ventilasi harus berukuran paling sedikit 10\% dari luas lantai. Salah satu cara yang dapat dilakukan untuk mengatasi luas ventilasi yang tidak memenuhi syarat antara lain, menambah lubang angin dan lubang-lubang pada dinding. Selain itu, hendaknya membiasakan membuka jendela setiap pagi dan siang hari agar cahaya matahari dan udara dapat masuk ke dalam ruangan.

\section{Lubang asap dapur}

Pada Tabel 1 juga terlihat bahwa jumlah rumah yang tidak ada lubang asap dapur sebanyak $72,0 \%$, rumah yang memiliki lubang asap dapur tetapi luasnya kurang dari $10 \%$ dari luas dapur sebanyak $25,3 \%$, dan rumah dengan lubang asap dapur memenuhi syarat kesehatan sebanyak $2,67 \%$.

Dapur harus menempati ruangan tersendiri karena asap hasil pembakaran (memasak dengan bahan bakar minyak) dapat berdampak terhadap kesehatan. Ruang dapur harus memiliki ventilasi dengan luas yang cukup, agar asap dari dapur mengalir keluar (Sukini dkk, 1989). Lubang asap dapur yang tidak memenuhi persyaratan menyebabkan gangguan terhadap pernafasan, membuat lingkungan rumah menjadi kotor, dan berbau (Depkes RI, 2000).

Sebaiknya setiap rumah memiliki lubang asap dapur yang memenuhi syarat yaitu minimal $10 \%$ dari luas lantai dapur. Pada saat memasak, sebaiknya jendela dan pintu ke arah luar dalam posisi terbuka, sehingga asap pembakar dapat keluar dengan cepat.

\section{Pencahayaan}

Hasil pengukuran pencahayaan dalam rumah mendapatkan sebanyak 21 rumah $(28,0 \%)$ masuk dalam kategori gelap ( $<50$ lux $)$, dan 37 rumah $(72,0 \%)$ masuk dalam kategori terang (50-100 lux).
Pencahayaan alami diperoleh dari masuknya sinar matahari ke dalam ruangan melalui jendela, celah-celah dan bagian-bagian bangunan yang terbuka. Sinar ini sebaiknya tidak terhalang oleh bangunan, pohon-pohon maupun tembok pagar yang tinggi. Selain sebagai sumber penerangan alami, sinar matahari juga berguna untuk meningkatkan suhu udara, mengurangi kelembaban, serta bersifat garmesida atau mampu membunuh mikroorganisme (Keman, 2005). Beberapa mikroorganisme yang dapat mati akibat terpapar sinar ultra violet dari matahari antara lain penyebab penyakit TBC, influenza, penyakit mata.

Pemenuhan kebutuhan cahaya untuk penerangan alami sangat ditentukan oleh letak dan lebar jendela. Untuk memperoleh jumlah cahaya matahari pada pagi secara optimal, sebaiknya jendela kamar tidur menghadap ke timur. Luas jendela yang baik minimal $10-20 \%$ luas lantai. Apabila luas jendela melebihi $20 \%$ dapat menimbulkan kesilauan dan panas, sebaliknya kalau terlalu kecil dapat menimbulkan suasana gelap dan pengap (Sukini dkk, 1898). Sebaiknya untuk memperoleh pencahayaan yang masih kurang dapat dilakukan dengan membiasakan untuk membuka jendela pada pagi dan siang hari dan dapat memasang genting kaca pada atap rumah.

\section{KESIMPULAN}

Secara umum, kondisi kesehatan perumahan masih kurang baik. Hasil penelitian mendapatkan $80 \%$ rumah tinggal belum dilengkapi langit-langit. Sebanyak 17,3\% dinding rumah masih semi permanen, dan $14,7 \%$ masih ditemukan dengan lantai tanah. Mayoritas rumah tinggal telah memiliki jendela kamar tidur $(85,3 \%)$ dan jendela pada ruang keluarga $(88,0 \%)$. Sehingga penerangan pada $72,0 \%$ rumah telah memenuhi syarat kesehatan (50-100 lux). Namun hanya 29,3\% rumah yang memiliki ventilasi memenuhi syarat kesehatan, dan sebagian besar $(72,0 \%)$ tidak memiliki lubang asap dapur.

\section{DAFTAR PUSTAKA}

Adnani, Hariza. 2011. Ilmu Kesehatan Masyarakat. Yogyakarta: Nuha Medika. 138 halaman.

Departemen Kesehatan dan Kesejahteraan Sosial RI. 2000. Modul Pelatihan Kualitas Lingkungan di Perumahan Bagi Kader 
Dasa Wisma. Jakarta: Direktorat Jendral PPM \& PL.

Entjang, Indan. 2000. Ilmu Kesehatan Masyarakat. Bandung: PT. Citra Aditya Bakti.

Keman, Soedjaji. 2005. Kesehatan Perumahan dan Lingkungan Permukiman Jurnal Kesehatan Lingkungan, FKM Unair.

Keputusan Menteri Kesehatan Republik Indonesia Nomor 829/Menkes/SK/VII/1999, Tentang Persyaratan Kesehatan Perumahan.

Notoatmodjo, Soekidjo. 2007. Kesehatan Masyarakat Ilmu \& Seni. Jakarta: Rineka Cipta.
2005. Metodelogi Penelitian

Kesehatan. Jakarta: Rineka Cipta.

Puskesmas Baradatu , 2014. Profil Puskesmas Baradatu, Way Kanan.

Riviwanto, Muchsin, dkk. 2011. Penyehatan Pemukiman. Yogyakarta: Gosyen Publishing. 210 halaman.

Sukini, Elisabeth, dkk. 1989. Pengawasan Penyehatan Lingkungan Pemukiman. Jakarta: DepKes RI Pusat Pendidikan Tenaga Kesehatan Proyek Pengembangan Pendidikan Tenaga Kerja Sanitasi Pusat. 210 halaman 